\title{
Specificity and $V_{H}$ sequence of two monoclonal antibodies against the $\mathrm{N}$-terminus of dystrophin
}

\author{
Glenn E. MORRIS, ${ }^{*}$ Christine NGUYEN and NGUYEN THI MAN \\ MRIC Biotechnology Group, North East Wales Institute, Deeside, Clwyd, CH5 4BR, U.K.
}

\begin{abstract}
We have used a random library of 15-mer peptides expressed on phage to show that two monoclonal antibodies (mAbs) require only the first three amino acids of dystrophin (Leu-Trp-Trp) for binding. Since the mAbs recognize dystrophin in frozen muscle sections, the results suggest that this hydrophobic $\mathrm{N}$-terminus of dystrophin is accessible to antibody in situ. Quantitative binding studies suggested minor differences in specificity between the two $\mathrm{mAbs}$, so the Ig heavy-chain variable region $\left(\mathrm{V}_{\mathrm{H}}\right)$ sequences of the two hybridomas were determined by RT-PCR and CDNA
\end{abstract}

sequencing. After elimination of PCR errors, the two cDNA sequences were found to be identical except for five somatic mutations which resulted in three amino acid changes in the second hypervariable region (CDR2). The results suggest that the two hybridomas originated from the same lymphocyte clone in a germinal centre of the spleen, but underwent different point mutations and subtype switches during clonal expansion to form blast cells.

\section{INTRODUCTION}

We recently described two monoclonal antibodies (mAbs), MANEX1A and MANEX1B, raised against the $\mathrm{N}$-terminus of muscle-specific dystrophin, the muscular dystrophy protein. They both recognize the same 10 -mer peptides and they both crossreact with another, non-dystrophin, protein in the brain [1]. Although this strongly suggests that both mAbs recognize the same epitope, there may be sequence differences in the $\mathrm{mAb}$ hypervariable, or complementarity-determining regions (CDR), which modulate mAb affinity and specificity [2]. However, the possibility that the two hybridomas are absolutely identical, having arisen from identical progeny of a proliferative lymphocyte division in the spleen, cannot be ruled out. This uncertainty is common in hybridoma work; for example, 15 out of $19 \mathrm{mAbs}$ against a central 934-amino-acid region of dystrophin were found to recognize the same 74-amino-acid sequence and further mapping has not succeeded in separating them, although there are indications that at least two different epitopes are involved $[3,4]$.

We have now investigated further the relationship between the two MANEX1 mAbs by cDNA sequencing of their heavy-chain CDRs (after RT-PCR amplification of hybridoma mRNAs) and by the use of a phage display library of random peptides to identify more precisely the dystrophin amino acids which form their epitopes. Phage display libraries have become powerful tools for studying protein-protein and protein-ligand interactions of all kinds [5]. By revealing which random peptides an antibody can bind to, the method shows not only which amino acids are important for $\mathrm{mAb}$ binding but also what variations from the true antigen sequence can be tolerated. The method can even provide information on some types of conformational epitope [6]. We now show that both MANEX1A and MANEX1B recognize the first three amino acids of dystrophin (Leu-TrpTrp), although they differ in the effect of adjacent amino acids on binding and in their apparent cross-reaction with unrelated peptides. The extent to which small differences in antibody specificity is reflected in CDR sequence differences cannot be predicted with any confidence. Previous studies of Ig sequences have shown that $\mathrm{mAbs}$ which recognize similar epitopes may have quite diverse CDR sequences [7,8], although, on the other hand, $\mathrm{mAbs}$ with the same fine specificities often do have similar CDR sequences [9]. The heavy-chain CDR sequences of MANEX1A and MANEX1B reveal three differences in CDR2 which might be wholly or partly responsible for observed differences in $\mathrm{mAb}$ specificity. The results provide an insight into the generation of antibody diversity in the spleen and illustrate the importance of establishing several similar antibody-producing cell lines if the fine specificity of the immune response is to be immortalized as hybridomas.

\section{MATERIALS AND METHODS}

\section{Materials}

The hybridoma cell lines used, MANEX1A and MANEX1B, have been described previously [1]. The pT7Blue T-vector kit for direct cloning of PCR products and transformation into NovaBlue competent Escherichia coli cells was obtained from Novagen Inc. (Madison, WI, U.S.A.). Reverse transcriptase (Superscript) was from Life Technologies (Paisley, Scotland) and Taq polymerase (SuperTaq) from Stratech (Luton, Beds., U.K.).

\section{Selection from a phage peptide library}

The 15-mer library (in the fUSE5 vector based on fd phage), sequencing primers and associated bacterial cell lines were a generous gift from Professor George P. Smith (University of Missouri, U.S.A.) and his screening protocols [5] were followed with minor modifications. All solutions were sterilized by membrane filtration or autoclaving.

Abbreviations used: CDR; complementarity-determining region; mAb; monoclonal antibody; $P E G$, poly(ethylene glycol); $V_{H}$, heavy-chain variable region.

* To whom correspondence should be addressed.

The nucleic acid sequences reported have been deposited in the EMBL, GenBank and DDBJ Nucleotide Sequence Databases under the accession numbers Z46661 and Z46662. 
Sterile 3-cm-diam. Petri dishes were coated directly with mAb $(10 \mu \mathrm{g} / \mathrm{ml}$ in Tris-buffered saline; TBS: $150 \mathrm{mM} \mathrm{NaCl}, 50 \mathrm{mM}$ Tris/ $\mathrm{HCl}, \mathrm{pH} 7.5$ ), partially purified from ascites fluid by $50 \%$ ammonium sulphate precipitation. After blocking with $4 \%$ BSA in TBS and washing, an aliquot of the phage library $\left(1.5 \times 10^{10}\right.$ transducing units) was added in $0.4 \mathrm{ml}$ of TBST $(0.5 \%$ Tween 20 in TBS) and incubated for $4 \mathrm{~h}$ at $4^{\circ} \mathrm{C}$ ('bio-panning'). Bound phage was eluted with glycine $/ \mathrm{HCl}, \mathrm{pH} 2.2$, amplified in $E$. coli strain K91Kan and recovered by precipitation with poly(ethylene glycol) (PEG 8000; Sigma). Two further rounds of bio-panning after amplification were performed and the final eluate was transduced into $\mathrm{K} 91 \mathrm{Kan}$ and streaked out overnight at $37^{\circ} \mathrm{C}$ on LB agar plates with tetracycline $(40 \mu \mathrm{g} / \mathrm{ml})$ and kanamycin $(100 \mu \mathrm{g} / \mathrm{ml})$. Phage titres were determined as transducing units by plating out 10 -fold serial dilutions of transduced K91Kan. Finally 10-20 clones were grown up and phage DNA was prepared by PEG precipitation and phenol/chloroform extraction. Sequencing was performed using Sequenase v.2.0 (USB/ Amersham International), ${ }^{35} \mathrm{~S}-\mathrm{dATP}$ (ICN: $1000 \mathrm{mCi} / \mathrm{mmol}$ ) and the primer, $5^{\prime}$-ccetcatagttagcgtaacg.

\section{Hybridoma CDNA preparation}

Total mRNA was prepared from $100 \mathrm{ml}$ of hybridoma cell culture (approx. $5 \times 10^{7}$ cells) by SDS lysis and oligo-dT adsorption (FastTrack kit, Invitrogen Corp., San Diego, CA, U.S.A.). After ethanol precipitation, the mRNA pellet was redissolved in $40 \mu \mathrm{l}$ of TE buffer $(10 \mathrm{mM}$ Tris $/ \mathrm{HCl}, \mathrm{pH} 8.0$, $1 \mathrm{mM}$ EDTA). Next $5 \mu \mathrm{l}$ of $\mathrm{mRNA}$ was heated to $65^{\circ} \mathrm{C}$ for $3 \mathrm{~min}$ with $5 \mu \mathrm{l}$ of water and $1 \mu \mathrm{l}$ of random hexamer primers (100 pmol) and cooled on ice before adding dithiothreitol to $10 \mathrm{mM}$, dNTPs to $0.5 \mathrm{mM}$ and buffer (final concentration $50 \mathrm{mM}$ Tris/ $\mathrm{HCl}, \mathrm{pH} 8.3,75 \mathrm{mM} \mathrm{KCl}, 3 \mathrm{mM} \mathrm{MgCl}_{2}$ ) to a final volume of $19 \mu$ l. Finally 200 units $(1 \mu \mathrm{l})$ of reverse transcriptase were added and incubated at $37^{\circ} \mathrm{C}$ for $1 \mathrm{~h}$, followed by $5 \mathrm{~min}$ at $95^{\circ} \mathrm{C}$. The mRNA purification step may be unnecessary since PCR amplification can also be achieved with total RNA.

\section{PCR amplification}

The primers used to amplify mouse Ig heavy-chain variable domains $\left(\mathrm{V}_{\mathrm{H}}\right)$ were: forward 5'-tgaggagacggtgaccgtggtccettggccccag and reverse $5^{\prime}-\operatorname{aggt}(\mathrm{c} / \mathrm{g})(\mathrm{a} / \mathrm{c}) \mathrm{a}(\mathrm{a} / \mathrm{g}) \operatorname{ctgcag}(\mathrm{c} / \mathrm{g}) \operatorname{agtc}$ (a/t)gg [10]. To $8 \mu \mathrm{l}$ of cDNA were added dNTPs $(50 \mu \mathrm{M})$, primers $(0.2 \mu \mathrm{M}), 10 \times$ buffer (final concn. $20 \mathrm{mM}$ Tris $/ \mathrm{HCl}$, pH 8.3, $25 \mathrm{mM} \mathrm{KCl}, 0.05 \%$ Tween $20,100 \mu \mathrm{g} / \mathrm{ml}$ nuclease-free BSA) and water to a final volume of $97 \mu \mathrm{l}$. After covering with mineral oil, the samples were heated to $94^{\circ} \mathrm{C}$ for $4 \mathrm{~min}$. Taq polymerase ( 3 units in $3 \mu \mathrm{l}$ ) was added and PCR was performed for 30 cycles on a thermal cycler $\left(1 \mathrm{~min}\right.$ at $72^{\circ} \mathrm{C}, 30 \mathrm{~s}$ at $55^{\circ} \mathrm{C}$ and $30 \mathrm{~s}$ at $94^{\circ} \mathrm{C}$ each cycle).

The whole reaction was subjected to electrophoresis in $2 \%$ low-melting-point agarose and the DNA band at approx. $350 \mathrm{bp}$ was excised and weighed. After melting at $80^{\circ} \mathrm{C}$ and addition of urea ( $4 \mathrm{~g} / \mathrm{g}$ of gel), DNA was recovered using a QIAGEN column and concentrated into $20 \mu \mathrm{l}$ of TE buffer using QIAEX resin according to manufacturer's protocols (Diagen, Dusseldorf, Germany).

\section{Cloning and sequencing}

A sample ( $50 \mathrm{ng}$; approx. $3 \mu \mathrm{l})$ of purified PCR product was ligated directly into $50 \mathrm{ng}$ of pT7Blue plasmid vector using T4 DNA ligase $\left(2.5\right.$ Weiss units) at $16^{\circ} \mathrm{C}$ for $4-5 \mathrm{~h}$ in a final volume of $10 \mu$ l. After transformation of competent NovaBlue $E$. coli cells with $1 \mu \mathrm{l}$ of ligation mixture, the bacteria were plated on
LB agar (ampicillin/tetracycline) pretreated with $35 \mu \mathrm{l}$ of 5-bromo-4-chloroindol-3-yl $\beta$-D-galactopyranoside $(50 \mathrm{mg} / \mathrm{ml}$ in dimethylformamide) and $20 \mu \mathrm{l}$ of $100 \mathrm{mM}$ isopropyl thiogalactoside (IPTG) per 90-mm-diam. plate.

White colonies (containing insert DNA) were screened directly by PCR using heavy-chain primers. Typically, 60-70\% of white colonies contained the 350 bp insert. Plasmid DNA was purified by lysozyme/alkaline SDS treatment and phenol/chloroform extraction and treated with $1 \mu \mathrm{g}$ of DNase-free pancreatic RNase overnight at $4^{\circ} \mathrm{C}$. After a second alkali denaturation and phenol/chloroform extraction, the plasmid was redissolved in $20 \mu \mathrm{l}$ of water. DNA sequencing of both strands was performed using heavy-chain primers or pT7Blue forward and reverse primers (forward 5'-taatacgactcactataggg; reverse 5 '-ggttttccagtcacgacg).

\section{RESULTS}

As a precaution against the isolation of non-specific phage clones, the library was panned sequentially against an uncoated dish (blocked with BSA) and an unrelated mAb (MANDYS18 against the dystrophin rod domain [4]) before panning against a dish coated with MANEX1A. After two further rounds of amplification and panning against MANEX1A, 14 clones which gave good sequencing data were obtained and the sequences of the 15-mer peptides being expressed by these clones are aligned with the dystrophin sequence in Figure 1. Twelve of the 14 clones gave 10 different sequences, all of which contained the threeamino-acid sequences, LWW (eight out of 10) or VWW (two out of 10), corresponding to the first three amino acids of the musclespecific isoform of dystrophin [1] (it seems a reasonable assumption, in view of our results, that the initiator methionine in the cDNA-derived sequence is absent from dystrophin in vivo).

Dystrophin: $\quad$ LWWEEVEDCYERED

1) L VR S P D A F L R LWWD

2) Y LWWAATDS A L V G

3) RWLSATAFPG LWWSS

4) G $\underline{L W W N D F V ~ T ~ T ~ L ~ A ~ L ~ G ~}$

5/6) G V VA D D R P Y V $\underline{W}$ V S

7/8) G G VALAPG LWWSEWR

9) PSLGS PWG V $\underline{W}$ SR DV

10) $\quad \mathrm{PWCVKGPQLWWSPWT}$

11) RDALAPG LWWSEWR

12) LAPG $\underline{L W W R E R}$

13) Q S A T T V S V N PA D F N

14) RS $\underline{F}$ LRGR $\underline{P}$ H I I I A

Figure 1 Peptide sequences isolated from a phage display library by biopanning with the MAb, MANEX1A

In the first 12 peptides (10 sequences), three amino acids (underlined) are shared with the dystrophin $\mathrm{N}$-terminal sequence. The last two peptides are apparently unrelated to either dystrophin or the other 10 sequences, though they have three amino acids in common with each other (underlined). 
Table 1 Quantfication of binding of two mAbs to various peptide sequences expressed on phage

Phage particles isolated by PEG precipitation were coated at similar titres in PBS on to microwell plates for ELISA as previously described [21]. After blocking with 4\% BSA, MANEX1 mAb culture supernatants were applied at a concentration of $1 / 1000$ and mAb binding was determined, after washing, using peroxidase-labelled rabbit anti-(mouse lg) (DAKOpatts Ltd) and o.phenylenediamine as substrate. The figures are absorbance values at $492 \mathrm{~nm}$ determined with a microplate reader and the peptide numbers are those used in Figure 1.

\begin{tabular}{llll}
\hline Peptide number & $\begin{array}{l}\text { MANEX1A } \\
\text { binding }\end{array}$ & $\begin{array}{l}\text { MANEX1B } \\
\text { binding }\end{array}$ & Ratio: 1B/1A \\
\hline 1 & 1.23 & 1.18 & 0.96 \\
2 & 1.03 & 1.66 & 1.61 \\
3 & 1.33 & 1.17 & 0.88 \\
4 & 1.29 & 1.06 & 0.82 \\
$5 / 6$ & 0.49 & 1.09 & 2.22 \\
& 0.42 & 0.89 & 2.13 \\
$7 / 8$ & 1.14 & 0.89 & 0.78 \\
& 1.04 & 0.84 & 0.81 \\
9 & 0.73 & 0.34 & 0.46 \\
13 & 0.40 & 0.00 & 0.00 \\
\hline
\end{tabular}

This shows that the two tryptophan residues are essential for MANEX1A binding, but a conservative substitution of Val-1 for Leu-1 is tolerated. There is no evidence from Figure 1 that subsequent amino acids in the dystrophin sequence play any specific role in MANEX1A binding. Since LWW is at the Nterminus of dystrophin, the frequent occurrence of structurally flexible Pro and Gly residues in the preceding amino-acid sequence of the peptides may be significant. The relative avidities of MANEX1A and MANEX1B for eight of the 12 different phage-displayed peptides were compared by ELISA (Table 1). The reliability of this method is illustrated by the reproducibility of the results with the two pairs of identical phage clones isolated (clones 5/6 and 7/8). MANEX1B bound to all seven peptides containing the LWW/VWW sequence. There is no evidence that the substitution of Val for Leu has any differential effect, though the presence of a preceding Tyr in clones 2 and 5/6 appears to affect MANEX1A binding adversely, but not MANEX1B binding. Two unrelated clones (13 and 14 in Figure 1) were selected from the library and these were recognized weakly by MANEX1A, but not at all by MANEX1B (Table 1). The two peptides do share a three-amino-acid motif, FXXXXPA, but this is not found in dystrophin.

To characterize antigen-binding sequences in the mAbs, PCR products were obtained by reverse transcription of total mRNA from MANEX1A and MANEX1B hybridoma cells and PCR amplification of cDNA using the heavy-chain variable region primers described by Orlandi et al. [10]. They were cloned directly into the pT7Blue T-tailed vector for DNA sequencing. To avoid sequence errors due to PCR misincorporation, two separate PCR reactions were performed. In the case of MANEX1A, a discrepancy between the two clones sequenced (C or A at position 166) was observed, so a third clone was sequenced to confirm the $C$ residue. (This third clone carried a different error, $\mathrm{T}$ to $\mathrm{A}$ at position 39 , and this is clearly a PCR error since it introduces a stop codon. The errors were present on both strands of the PCR products.) The two MANEX1B clones gave identical sequences. Figure 2 shows an alignment of the MANEX1A and MANEX1B cDNA consensus sequences; only DNA between the two PCR primers is shown, although the PCR primer sequences encode part of the variable domain. There are

\section{GGCTTAGTGAAGCCTGGAGGGTCCCTGAAACTCTCCTGTGCAGTCTCTGGATTCACTTTTAGTAGTTATGCCATG GGCTTAGTGAAGCCTGGAGGGTCCCTGAAACTCTCCTGTGCAGTCTCTGGATTCACTTTCAGTAGTTATGCCATG TCTTGGGTTCGCCAGACTCCAGAGAAGAGGCTGGAGTGGGTCGCATCCATTAÄAGTGGTGGTAGAACCTACTAT TCTTGGGTTCGCCAGACTCCAGAGAAGAGGCTGGAGTGGGTCGCATCCATTAGTAGTGGTGGTAGAACCTACTAT * * * * CCAGACGGTGTGAAGGGCCGATTCACCATCTCCAGAGTCAGGAACATCCTGTACCTGCAAATGAACAGTCTGAGG TTAGACAGTGTGAAGGGCCGATTCACCATCTCCAGAGTCAGGAACATCCTGTACCTGCAAATGAACAGTCTGAGG} TCTGAGGACACGGCCATGTATTACTGTGCAAGAGGCTACTATGGAAACTAC TCTGAGGACACGGCCATGTATTACTGTGCAAGAGGCTACTATGGAAACTAC

MANEX1A

MANEX1B

Figure 2 Comparison of the nucleotide sequences of MANEX1A and $1 \mathrm{~B}$ ig heavy-chain variable domains

Variable domain sequences contributed by the two PCR primers $\left(30\right.$ nt $5^{\prime}$ and 6 nt $\left.3^{\prime}\right)$ are not shown.

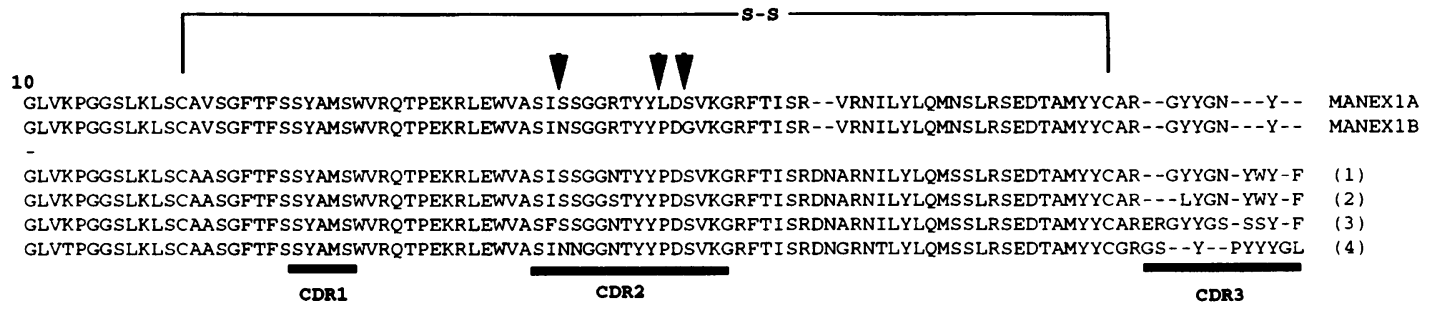

Figure 3 Amino-acid sequences of MANEX1A and 1B Ig heavy-chain variable domains and comparison with four similar sequences from the database

Amino-acid sequences run from residue 10 of the heavy chain to almost the end of the CDR3 region; the last two amino acids in all six sequences having been omitted because they were determined by the PCR primer. The disulphide bridge and the three CDR regions are shown. Three amino acid differences between MANEX1A and 1B are shown by arrows. Ig sequences $1-4$ are those most similar to MANEX1A found by a BLASTP search of the GenBank, EMBL, PIR and Swissprot databases. The antigens recognized by the mAbs are: (1) influenza virus haemagglutinin ([8]; X59192), (2) morphine ([19]; M92390), (3) glycophorin A (S. L. Spitalnik, unpublished work; U01850), (4) tobacco mosaic virus protein ([20]; M34893). 
only five nucleotide differences after PCR errors have been eliminated; one at position 60 is close to CDR1 and does not cause an amino-acid change, while the other four are within the region encoding CDR2 and cause three amino acid changes.

The amino-acid-sequence translations are shown in Figure 3 where they have been aligned with four of the most similar sequences found by a database search (BLASTP). The antigens recognized by these four mAbs bear little relation to dystrophin or to each other. The $V_{H}$ regions belong to the $V_{H} 7183$ gene family of Brodeur and Riblet [11] and the III D subgroup of Kabat et al. [12]. Most of the amino-acid variations between MANEX1 mAbs and the archetypal $V_{\mathbf{H}} 7183$ sequence have been observed in other mAbs, including Asn-51, Leu-60, Val-74 and Asn-83. The deletion of Asp-72-Asn-73 in the third framework region appears to be a novel mutation, although deletion of Asp72 alone has been reported previously in several mAbs [12]

\section{DISCUSSION}

In an earlier study using overlapping synthetic 10-mer peptides, we showed that both MANEX1 mAbs recognized MLWWEEVEDC and WWEEVEDCYE, but not EEVEDCYERE [1]. This showed that the two tryptophan residues are essential, but left open the question of whether any of the amino acids EEVEDC are also involved. The present results show that only the LWW sequence is involved in MANEX1 binding by dystrophin. The mAbs were obtained from mice immunized with a $\beta$-galactosidase fusion protein in which plasmid-encoded residues and the initiator Met residue (DSRGIPM) preceded the LWW sequence [1]. The peptide sequences in Table 1 contain no Met residues, suggesting that the initiator Met is removed from dystrophin post-translationally, as it is from the majority of mammalian proteins. Many of them contain the preceding Pro, however, and peptides 5/6 also have a DSR sequence (Figure 1). LWW is rather small for a protein epitope and this result suggests that the epitope in the fusion protein may be somewhat larger, the $\mathrm{mAb}$ binding to dystrophin being a reaction with only part of the epitope (although clearly the most important part). One might expect such mAbs to be uncommon and, indeed, only one out of three mice which gave a strong antibody response to the fusion protein produced antibodies which could recognize authentic dystrophin on Western blots and frozen muscle sections [1]. The possibility that the proline is merely providing a flexibility requirement to the peptides, together with nearby glycines, cannot be ruled out. The in situ accessibility of the LWW sequence in dystrophin as judged by antibody binding to air-dried, untreated, frozen muscle sections [1], suggests that these very hydrophobic residues are not buried deeply within the dystrophin molecule, as one might expect. An amino-acid sequence close to the $\mathrm{N}$-terminus of dystrophin (only 14 amino acids after LWW) is thought to be involved in its interaction with actin [13] and this interaction might act as a constraint on the disposition of the LWW sequence.

The results in Table 1 show that the two MANEX1 mAbs differ slightly in their specificity since some peptides bind MANEX1A more strongly, while others prefer MANEX1B. Furthermore, only MANEX1A recognizes two apparently unrelated sequences (clones 13 and 14 in Figure 1).

The $V_{H}$ sequences show that the two MANEX1 hybridomas have the same genetic rearrangement but have diverged subsequently through somatic mutation and subtype switching events. MANEX1A is an IgG2a, while MANEX1B is an IgG2b [1]. In cellular terms, it seems likely that they originated from the same lymphocyte clone in a germinal centre of the spleen, but have undergone different point mutations and subtype switches during clonal expansion to form blast cells [14]. We have not sequenced the light-chain mRNAs, so there may be more differences between the two mAbs than our results show. Of the heavy-chain CDRs, CDR3 is the most variable and is thought to make the greatest contribution to antibody specificity [15]. It is significant, therefore, that both MANEX1 mAbs share the same CDR3 sequence which is different from all other CDR3s in the sequence databases. In 10 antibody-antigen complexes of known three-dimensional structure, only residues from the $\mathrm{N}$-terminal and central parts of CDR2 are involved in antigen binding, suggesting that, of the three amino acid differences between MANEX1A and MANEX1B, the substitution of Asn-52 for Ser-52 is likely to have the greatest effect on antibody avidity and specificity; this is a contact residue in eight of the 10 three-dimensional structures determined [2]. Some comment is required on the notable sequence similarity with an $\mathrm{mAb}$ against influenza virus haemagglutinin (Figure 3). First, it is not unusual for mAbs to crossreact with apparently unrelated antigens; in this case, crossreactivity has not been tested. Secondly, their light-chain CDR sequences, which are not available, may differ more significantly than their heavy-chain CDRs. Finally, both MANEX1 mAbs have a deletion of Asp-Asn (DN) in the third framework region (Figure 3) and this Asn residue is known to form contacts with CDRs in some mAbs and to affect their conformation [2]. Since such contacts can influence CDR topography and hence ligand binding, this deletion may play a role in determining the specificity of the MANEX1 mAbs.

Because only minor sequence differences, if any, are expected between mAbs with similar, if not identical, specificities, it is especially important to ensure that there are no errors in cDNA sequencing. PCR does introduce errors, though their frequency is affected by the type of polymerase and the reaction conditions [16]. Direct sequencing of PCR products is possible and has the advantage of helping to eliminate errors by producing an 'average' sequence for all the PCR product molecules. We elected to clone PCR products into a T-overhang vector, pT7Blue, which enables rapid and reproducible sequencing using unlabelled primers from the pT7Blue sequence, and to sequence at least two clones from separate PCR reactions in order to eliminate possible PCR errors. Provided PCR errors are both fairly uncommon and fairly random, the chance of two clones from different PCR reactions containing the same PCR error is extremely low.

It is intriguing that recent advances in understanding B-cell maturation enable us to envisage how the MANEX1A and MANEX1B hybridomas are likely to have diverged within the same B-cell lineage. In germinal centres, only B cells with highaffinity antibodies, refined by somatic mutation, are selected for Ig class-switching from IgM to another subtype and maturation as plasma or memory B cells [14]. The question of how many identical $B$ cells (i.e. with identical variable region sequences) can accumulate in the spleen, especially under conditions of secondary stimulation used for hybridoma production, is difficult to address, but is clearly relevant to how frequently identical mAbs will be obtained. From a practical point of view, the results appear to justify our policy of producing and cloning large numbers (20-25) of hybridomas for each immunogen $[4,17,18]$, if there are small differences in avidity and specificity between individual mAbs mapping to the same epitope.

This work was supported by grants from the Muscular Dystrophy Group of Great Britain and Northern Ireland and by DevR funding from the Higher Education Funding Council (Wales). We thank Professor George P. Smith for the peptide library and the Human Genome Mapping Project (Cambridge, U.K.) for use of computer facilities. 


\section{REFERENCES}

1 Le Thiet Thanh, Nguyen thi Man, Love, D. R., Helliwell, T. R., Davies, K. E. and Morris, G. E. (1993) Am. J. Hum. Genet. 53, 131-139

2 Padlan, E. A. (1994) Mol. Immunol. 31, 169-217

3 Sedgwick, S. G., Nguyen thi Man, Ellis, J. M., Crowne, H. and Morris, G. E. (1991) Nucleic Acids Res. 19, 5889-5894

4 Nguyen thi Man and Morris, G. E. (1993) Am. J. Hum. Genet. 52, 1057-1066

5 Scott, J. K. and Smith, G. P. (1990) Science 249, 386-390

6 Balass, M., Heldman, Y., Cabilly, S., Givol, D., Katchalskikatzir, E. and Fuchs, S. (1993) Proc. Natl. Acad. Sci. U.S.A. 90, 10638-10642

7 Clarke, S. H., Staudt, L. M., Kavaler, J., Schwart, D., Gerhard, W. and Weigert, M. G. (1990) J. Immunol. 144, 2795-2801

8 Stark, S. E. and Caton, A. J. (1991) J. Exp. Med. 174, 613-624

9 Kavaler, J., Caton, A. J., Staudt, L. M., Schwartz, D. and Gerhard, W. (1990) J. Immunol. 145, 2312-2321

10 Orlandi, R., Gussow, D. H., Jones, P. T. and Winter, G. (1989) Proc. Natl. Acad. Sci. U.S.A. 86, 3833-3837

11 Brodeur, P. H. and Riblet, R. (1984) Eur. J. Immunol. 14, 922-930
12 Kabat, E. A., Wu, T. T., Perry, H. M., Gottesman, K. S. and Foeller, C. (1991) Sequences of Proteins of Immunological Interest, 5th edn., U.S. Department of Health and Human Services, National Institutes of Health, Bethesda

13 Fabbrizio, E., Bonetkerrache, A., Leger, J. J. and Mornet, D. (1993) Biochemistry 32, 10457-10463

14 Clark, E. A. and Ledbetter, J. A. (1994) Nature (London) 367, 425-428

15 Stewart, E. A. and Schwart, R. S. (1994) Blood 83, 1717-1730

16 Eckert, K. A. and Kunkel, T. A. (1991) in PCR. A Practical Approach (McPherson, M. J., Quirke, P. and Taylor, G. R., eds.), p. 225, IRL Press at Oxford University Press, Oxford

17 Nguyen thi Man, Ellis, J. M., Love, D. R., Davies, K. E., Gatter, K. C., Dickson, G. and Morris, G. E. (1991) J. Cell Biol. 115, 1695-1700

18 Nguyen thi Man, Ginjaar, I. B., Vanommen, G. J. B. and Morris, G. E. (1992) Biochem. J. 288, 663-668

19 Sawada, J., Yamazaki, T. and Terao, T. (1993) Mol. Immunol. 30, 77-86

20 Andria, M. L., Levy, S. and Benjamini, E. (1990) J. Immunol. 144, 2614-2619

21 Nguyen thi Man, Cartwright, A. J., Andrews, K. A. and Morris, G. E. (1989) J. Immunol. Methods 125, 251-259

Received 22 November 1994/8 February 1995; accepted 10 March 1995 